Nuclear Science and Technology Division

\title{
Corrosion Test Results for Inconel 600 vs Inconel-Stainless UG Bellows
}

\author{
P. E. Osborne* \\ A. S. Icenhour \\ G. D. Del Cul
}

Date Published: August 2002

Prepared by the OAK RIDGE NATIONAL LABORATORY

Oak Ridge, Tennessee 37831-6285

managed by

UT-BATTELLE, LLC

for the

U.S. DEPARTMENT OF ENERGY

under contract DE-AC05-00OR22725

*A4 Engineering, Inc., Knoxville, Tennessee 


\section{CONTENTS}

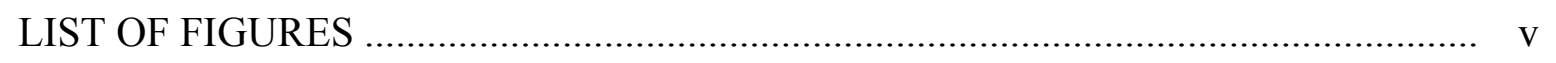

LIST OF TABLES ......................................................................................... vii

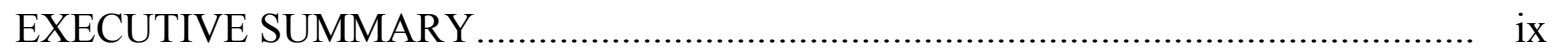

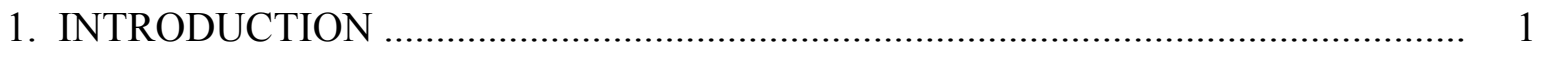

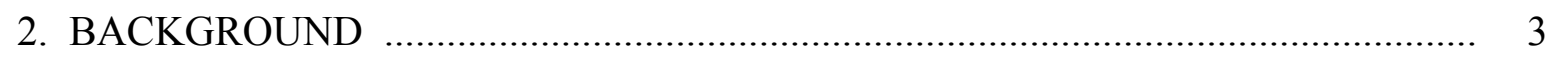

3. EXPERIMENTAL PROCEDURE ................................................................ 6

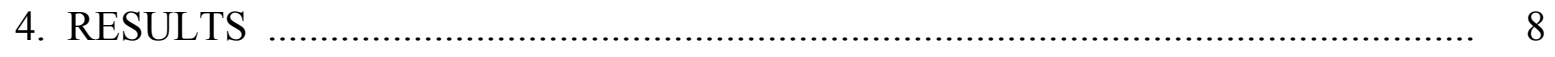

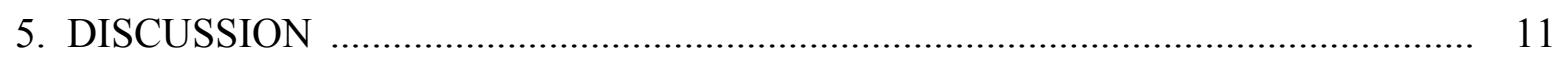

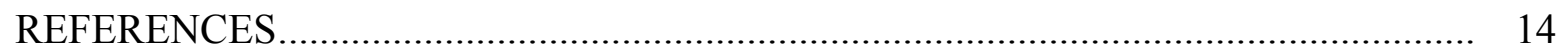




\section{LIST OF FIGURES}

Figure $\quad$ Page

1 Schematic of the HF handling system..................................................... 2

2 Comparison of corrosion rate of alloys in HF vapor and liquid ........................ 5

3 New bellows assemblies, showing wax-coated tips........................................ 7

4 Bellows C (left) and D (right) at the end of testing (28 days)........................... 9

5 Corrosion test results for Inconel bellows.................................................... 10

6 Comparison of bellows A (left) and B (right) after $32 \mathrm{~h}$ of HF exposure............. 11

7 Percent weight change in corrosion testing of new unplated, old unplated,

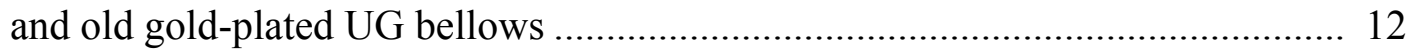




\section{LIST OF TABLES}

Table

Page

1 Approximate chemical compositions of selected alloys .................................. 3

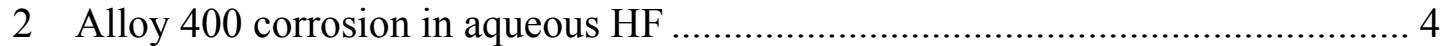

3 Hastelloy C-276 corrosion in aqueous HF ....................................................... 5 


\section{EXECUTIVE SUMMARY}

The Conversion Project (CP) of the Molten Salt Reactor Experiment at Oak Ridge National Laboratory (ORNL) involves converting slightly less than $40 \mathrm{~kg}$ of ${ }^{233} \mathrm{U}$ to a stable form for safe storage. The operation is performed within a few vessels interconnected by valves and 1/2-in. metal tubing. During this conversion, a particularly toxic and corrosive by-product is formed, namely aqueous hydrofluoric acid (HF). The production of $\mathrm{HF}$ is a result of the hydrolysis of $\mathrm{UF}_{6}$ and subsequent steam treatments of $\mathrm{UO}_{2} \mathrm{~F}_{2}$. For each mole of $\mathrm{UF}_{6}$ converted, 6 mol of $\mathrm{HF}$ are produced. The HF that forms during conversion combines with water to produce approximately $1.5 \mathrm{~L}$ of $33 \mathrm{wt} \% \mathrm{HF}$. As this mixture is transferred within the process system, the tubing and valves are exposed to high concentrations of $\mathrm{HF}$ in liquid and vapor form.

Of particular concern in the system are the almost 30 valves that have the potential for exposure to HF. For these valves, a vendor-supplied UG valve was installed. UG valves consist of an Alloy 400 (Monel) body and stem tip and Alloy 600 (Inconel) bellows.

These valves have been used under experimental conditions that simulate the CP. It has been established that they have a finite life when exposed to a HF and air environment. Most failures were seen around the flange at the bottom of the bellows, and it was suspected that this flange and the weld material were not Inconel. In December 2001, the vendor confirmed that this flange was not Inconel but instead was stainless steel 316. After discussions between the vendor and ORNL staff involved with the CP effort, it was decided that the entire wetted area of the bellows would be fabricated from Alloy 600. In March 2002, four newly fabricated bellows assemblies were received from the vendor for the purposes of corrosion testing in HF. This report presents results from the corrosion tests conducted to determine if the new design of the bellows would enhance their corrosion resistance.

Four of the new bellows assemblies (A, B, C, and D) were partially immersed in $33 \% \mathrm{HF}$ at ambient temperature for 28 days. The assemblies were divided into two groups and held in separate beakers to avoid cross-contamination. Two of the bellows were ultrasonically cleaned before drying and weighing, while the others were dried 
and weighed without cleaning. All four bellows were exposed to HF for approximately $16 \mathrm{~h}$ before being removed and air dried.

Bellows B experienced immediate and severe corrosion. On the second day, the flange was lost when the bellows corroded completely through at one convolution. The bellows lost a total of $9.5 \mathrm{wt} \%$ in 2 days and was later determined to be stainless steel with an Inconel 600 flange.

Bellows $\mathrm{A}$ and $\mathrm{C}$ were not cleaned, and corrosion deposits accumulated on them as is expected in the CP. At the end of 1 week, no weight had been lost. At the end of 4 weeks, the bellows were removed and ultrasonically cleaned in warm water, although the deposits were largely unaffected. Bellows A was manually scraped and yielded $1.34 \mathrm{~g}$ of corrosion products. This resulted in a loss of $4.16 \mathrm{wt} \%$. Bellows $\mathrm{C}$ was estimated to have approximately the same amount of corrosion with a loss of $5.99 \mathrm{wt} \%$. Weight loss appeared to be less pronounced on bellows $\mathrm{A}$ and $\mathrm{C}$ due to partial protection from the corrosion deposit.

Bellows D was ultrasonically cleaned daily for the first 7 days and then cleaned weekly after that time. It lost almost $3 \mathrm{wt} \%$ the first week and about $8.5 \mathrm{wt} \%$ during the entire test.

The Inconel bellows lost between 4 and $8.5 \mathrm{wt} \%$ over the 28 -day test. Approximately $1-2 \%$ of this loss can be attributed to the protective wax coating that was placed over the stainless steel tip. The final weight loss was much less than that experienced in previous immersion studies involving Inconel-stainless bellows. Even gold-plated Inconel-stainless bellows tended to lose approximately 25 wt \% when exposed to the same conditions.

The new all-Inconel bellows performed much better than the old Inconel-stainless bellows in concentrated HF liquid and vapor. It is expected that they would last much longer in the CP than the previous bellows did. 


\section{INTRODUCTION}

The Conversion Project (CP) of the Molten Salt Reactor Experiment at Oak Ridge National Laboratory (ORNL) involves converting slightly less than $40 \mathrm{~kg}$ of ${ }^{233} \mathrm{U}$ to a stable form for safe storage. The operation is performed within a few vessels interconnected by valves and 1/2-in. metal tubing. During this conversion, a particularly toxic and corrosive by-product is formed, namely aqueous hydrofluoric acid (HF). The production of $\mathrm{HF}$ is a result of the hydrolysis of $\mathrm{UF}_{6}$ and subsequent steam treatments of $\mathrm{UO}_{2} \mathrm{~F}_{2}$. For each mole of $\mathrm{UF}_{6}$ converted, $6 \mathrm{~mol}$ of $\mathrm{HF}$ are produced. Not only can extremely limited exposures to HF prove fatal, but HF has also been well documented to corrode most metals, glass, elastomers, and ceramics in a short period of time.

The concentrated HF that forms during processing is first transferred to a condenser under vacuum. Process tubing is kept at $200^{\circ} \mathrm{C}$ to avoid condensation. The HF is then flowed into an evaporator, which is subsequently heated under vacuum, and the HF is collected in a second condenser. This second evaporation/condensing step is used to purify the HF of any potential radioactive contaminants or corrosion products. The HF is then transferred into a trap, where it is reacted with soda lime to produce an acceptable waste for disposal. Figure 1 is a schematic of the HF handling system of the CP.

The HF that forms during conversion combines with water to produce approximately $1.5 \mathrm{~L}$ of $33 \mathrm{wt} \% \mathrm{HF}$. As this mixture is transferred within the process system, the tubing and valves are exposed to high concentrations of $\mathrm{HF}$ in liquid and vapor form. At the completion of the transfer, a nitrogen sweep is used to clean the tubing. However, some sections are also exposed to a wet air purge, and periodic maintenance is expected to briefly expose most areas to air at one time or another.

The HF part of the conversion system consists of Hastelloy C-276 and Monel 400 (Alloy 400) tubing, Haynes 230 and Hastelloy C-276 vessels, and Alloy 400 valves with Inconel (Alloy 600) bellows. The chemical compositions of the metals discussed in this report are listed in Table 1. Of particular concern in the system are the almost 30 valves that have the potential for exposure to HF. For these valves, a vendor-supplied UG valve was installed. These valves consist of an Alloy 400 body and stem tip and Alloy 600 bellows. The body, stem tip, and bellows were electrolessly plated with gold on all wetted surfaces to provide an extra layer of protection. 


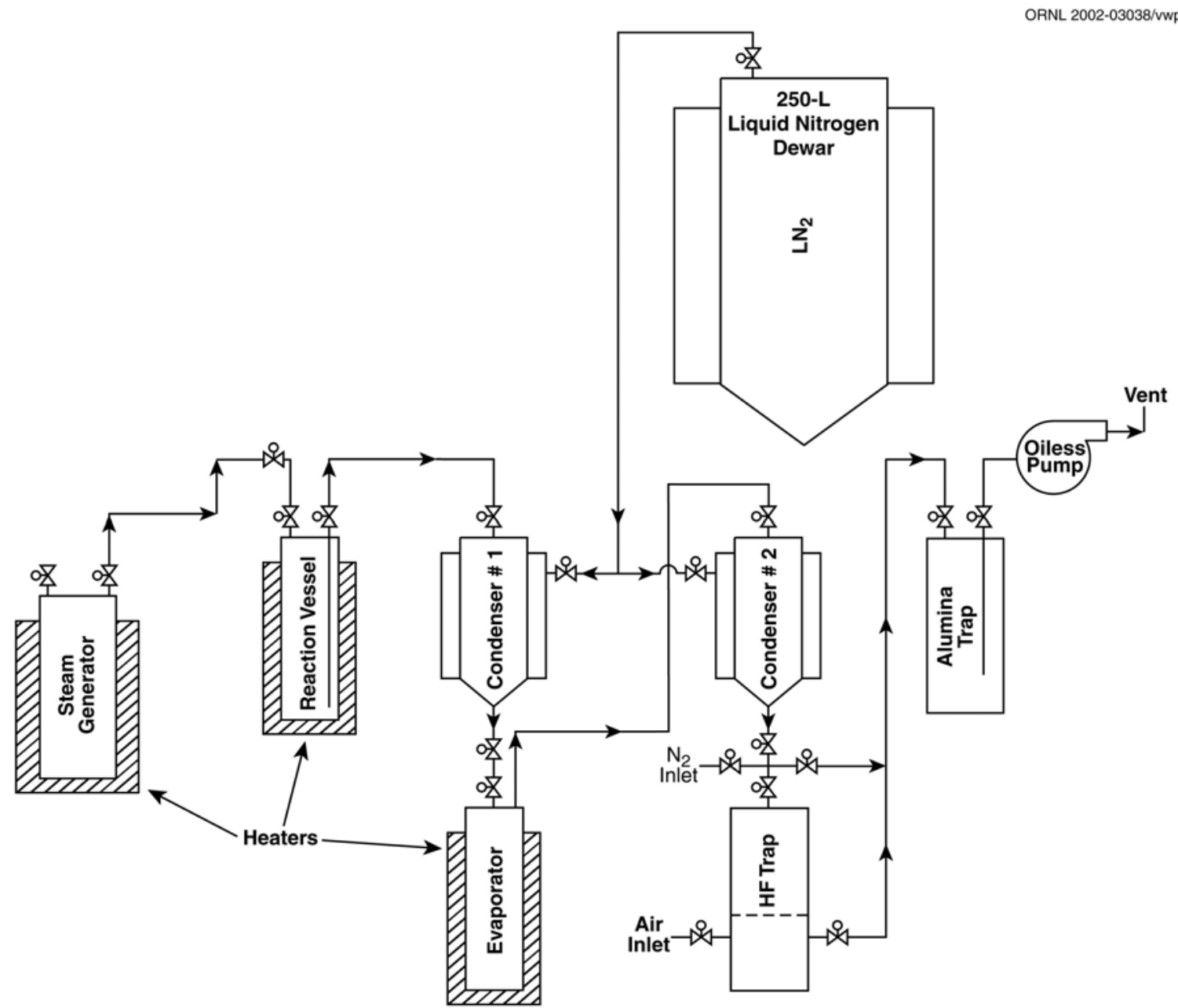

Fig. 1. Schematic of the HF handling system.

For at least the last 3 years, these valves have been used under experimental conditions that simulate the CP. It has been established that they have a finite life when exposed to a HF and air environment. Most failures were seen around the flange at the bottom of the bellows, and it was suspected that this flange and the weld material were not Inconel. In December 2001, the vendor confirmed that this flange was not Inconel but instead was stainless steel 316. This material is known to experience severe corrosion in HF and is not recommended for use in this application. After discussions between the vendor and ORNL staff involved with the CP effort, it was decided that the entire wetted area of the bellows would be fabricated from Alloy 600. In March 2002, four newly fabricated bellows assemblies were received from the vendor for the purposes 
of corrosion testing in HF. This report presents results from corrosion tests conducted to determine if the new design of the bellows would enhance their corrosion resistance.

Table 1. Approximate chemical compositions of selected alloys

\begin{tabular}{cc}
\hline Alloy & Composition (wt \%) \\
\hline Monel 400 & $67 \mathrm{Ni}-31.5 \mathrm{Cu}-1.2 \mathrm{Fe}$ \\
Inconel 600 & $76 \mathrm{Ni}-15.5 \mathrm{Cr}-8 \mathrm{Fe}$ \\
Hastelloy C-276 & $57 \mathrm{Ni}-16 \mathrm{Cr}-16 \mathrm{Mo}-4 \mathrm{~W}$ \\
Stainless steel 316 & $12 \mathrm{Ni}-17 \mathrm{Cr}-2.5 \mathrm{Mo}-1-2 \mathrm{Mn}-65 \mathrm{Fe}$ \\
\hline
\end{tabular}

Source: R. B. Rebak, J. R. Dillman, P. Crook, and C.V.V. Shawber, "Corrosion Behavior of Nickel Alloys in Wet Hydrofluoric Acid," Mater. Corros. 52, 289-297 (2001).

\section{BACKGROUND}

The effect of HF on metals under different conditions and stressors has been widely documented. Some parameters that can have a major effect on the corrosion rate are aeration or oxygen concentration of the HF, liquid vs vapor exposure, HF concentration, temperature, agitation, flow, and erosion.

Alloy 400 is one of the best-documented materials with respect to HF exposure. Its corrosion rate is highly dependent on temperature, HF concentration, and oxygen concentration. $^{1-3}$ When immersed in aqueous HF, Alloy 400 suffers little or no attack. In aerated vapor, however, it suffers severe corrosion and stress corrosion cracking, presumably due to the accretion of cupric fluorides. ${ }^{2,3}$ Pawel reported corrosion rates an order of magnitude higher in aerated vapor than in immersed samples, ${ }^{2}$ and Schussler found corrosion rates 20-100 times higher than those experienced by immersed samples. ${ }^{4}$ Both studies found the corrosion to be greatly decreased when vapor exposure occurred in a nitrogen purge. Two studies performed by the Nickel Development Institute reflect the importance of oxygen in Alloy 400 corrosion (see Table 2). Aqueous and vapor exposures at temperatures greater than $100^{\circ} \mathrm{C}$ have been shown to contribute to a much higher corrosion rate in Alloy 400. One study recommended against the use of Alloy 400 in HF-related operations at temperatures higher than $120^{\circ} \mathrm{C}$. Table 2 shows the correlation of temperature and corrosion for this alloy. ${ }^{3}$ 
Table 2. Alloy 400 corrosion in aqueous HF

\begin{tabular}{ccccc}
\hline Temp $\left({ }^{\circ} \mathrm{C}\right)$ & HF conc. & \multicolumn{2}{c}{ Corrosion $\left(\mathrm{mpy}^{a}\right)$} & Purge gas \\
\cline { 3 - 4 } & $(\%)$ & Liquid & Vapor & \\
\hline 30 & 25 & 2.4 & Nitrogen \\
30 & 25 & 11 & Air \\
80 & 25 & 0.2 & & Nitrogen \\
80 & 25 & 37 & & Air \\
130 & 40 & 11 & 1 & Nitrogen \\
130 & 40 & 22 & 1000 & Air \\
\hline
\end{tabular}

${ }^{a}$ Mils per year.

Austenitic stainless steels such as Alloy 316 do poorly in the presence of HF. They are resistant to anhydrous HF but undergo severe corrosion even in dilute HF. One study found that stainless steel 316 was corroded at a rate of 700 mils per year (mpy) in impure $12 \mathrm{wt} \% \mathrm{HF}$ at $83^{\circ} \mathrm{C}$ and approximately 2000 mpy when immersed in unaerated $38 \mathrm{wt} \%$ $\mathrm{HF}$ at $110^{\circ} \mathrm{C}$ (ref. 5). Figure 2 shows the corrosion rate of $254 \mathrm{SMO}$, which is similar in chemical composition to stainless steel 316 , in comparison with those of other potential alloys.

The alloy of preference for use in the harshest HF environments is Hastelloy Alloy C-276. Alloy C-276 has shown an overall superiority to most other alloys in the presence of HF. It is adversely affected by temperature, HF concentration, and oxygen availability but not to the extent of Alloy 400. (Note: Only recently has the vendor begun to manufacture Hastelloy UG valves. These valves were not available when the conversion process was fabricated.) One study found that the corrosion rate of Alloy C-276 decreased when the alloy was immersed in dilute aqueous HF as time increased from 2 to 14 days. ${ }^{1}$ This decrease was attributed to the formation of partially protective fluoride films. Two studies reported by the Nickel Development Institute indicate the effect of HF concentration, temperature, and oxygen on the corrosion of Alloy C-276. These results are summarized in Table 3. 


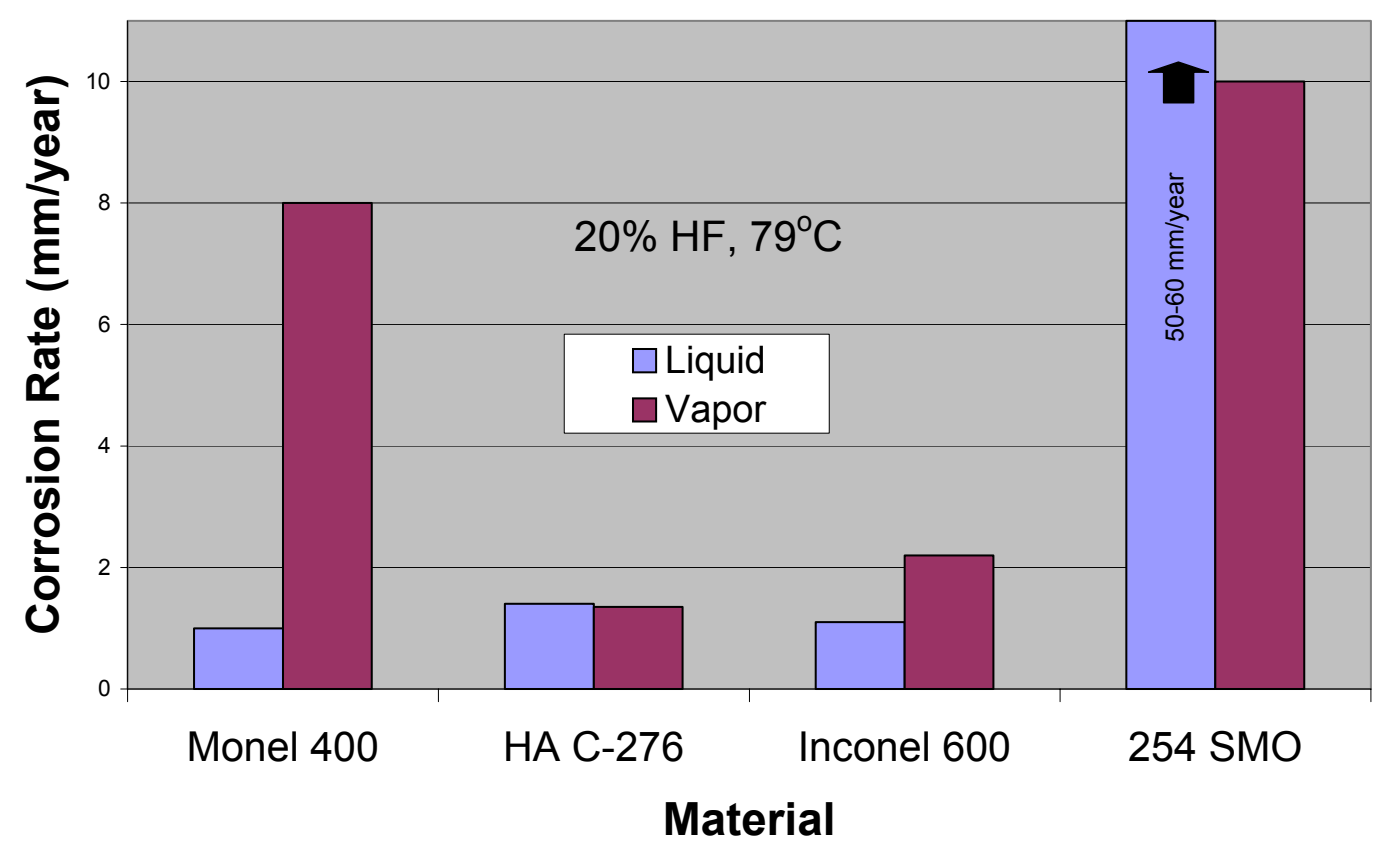

Fig. 2. Comparison of the corrosion rate of alloys in HF vapor and liquid. Adapted from R. B. Rebak, J. R. Dillman, P. Crook, and C. V. V. Shawber, "Corrosion Behavior of Nickel Alloys in Wet Hydrofluoric Acid," Mater. Corros. 52, 289-297 (2001).

Table 3. Hastelloy C-276 corrosion in aqueous HF

\begin{tabular}{ccccc}
\hline Temperature $\left({ }^{\circ} \mathrm{C}\right)$ & HF conc. & \multicolumn{2}{c}{ Corrosion $(\mathrm{mpy})^{a}$} & Purge gas \\
\cline { 3 - 4 } & $(\%)$ & Liquid & Vapor & \\
\hline 23 & 40 & 2.9 & & Air \\
54.5 & 40 & 10 & & Air \\
60 & 50 & 29 & 24 & Nitrogen \\
60 & 50 & 180 & 66 & Air \\
\hline
\end{tabular}

${ }^{a}$ Mils per year. 
The final alloy, and the one of particular concern in this study, is Inconel or Alloy 600. Rebak et al. ${ }^{1}$ reported that Alloy 600 underwent intergranular attack when immersed in aqueous HF, with a corrosion rate of about 39 mpy. ${ }^{1}$ The Nickel Development Institute reported that Alloy 600 was resistant to dilute aqueous solutions at ambient temperatures but may experience significant corrosion in hot aqueous solutions. ${ }^{5}$ Another study confirmed this result and reported a 9-mpy corrosion rate for an Alloy 600 sample in impure $12 \% \mathrm{HF}$ at $83^{\circ} \mathrm{C}$. This same study reported a 12 -mpy corrosion rate for Alloy 400 and a 700-mpy corrosion rate for stainless steel 316 (ref. 5). Schillmoller recommended Alloy 600 in place of Alloy 400 in applications where temperatures exceed $150^{\circ} \mathrm{C}$ (ref. 3). Alloy 600 performs slightly worse in moist aerated HF vapor than when immersed. Studies show a corrosion rate of 80-120 mpy and intergranular attacks and voids forming in a vapor environment. ${ }^{1}$ Figure 2 summarizes the performance of Alloy 600 in comparison with those of other alloys at $79^{\circ} \mathrm{C}$.

\section{EXPERIMENTAL PROCEDURE}

In the past, many experiments were performed in support of the $\mathrm{CP}$ to determine the corrosion performance of a variety of metals and polymers that might be used in the system. Because of time constraints, it was decided to run a very simple corrosion test involving immersion of the samples in concentrated (33 wt \%) HF at ambient temperatures and pressures. The bellows assemblies received from the vendor had been cleaned and triple packaged and were carefully handled to avoid contamination. It was decided that four bellows assemblies would be tested in a side-by-side test. Because of the extremely high corrosion rate of stainless steel in HF, the stainless steel tips (which are not a normally wetted surface) were dipped in molten wax (Fig. 3) to protect this area from the HF vapors.

Testing involved cycles of partial immersion of the bellows assemblies in 33\% HF in separate beakers for approximately $16 \mathrm{~h}$ and removing them to dry in air for about $8 \mathrm{~h}$.

The bellows were removed and dried, and the corrosion was measured by weight loss and visual inspection. These cycles ran daily for 7 days before moving to a once-a-week 
cycle of removal, cleaning, drying, and weighing for the next 3 weeks. The beakers were periodically topped off with fresh HF solution as needed.

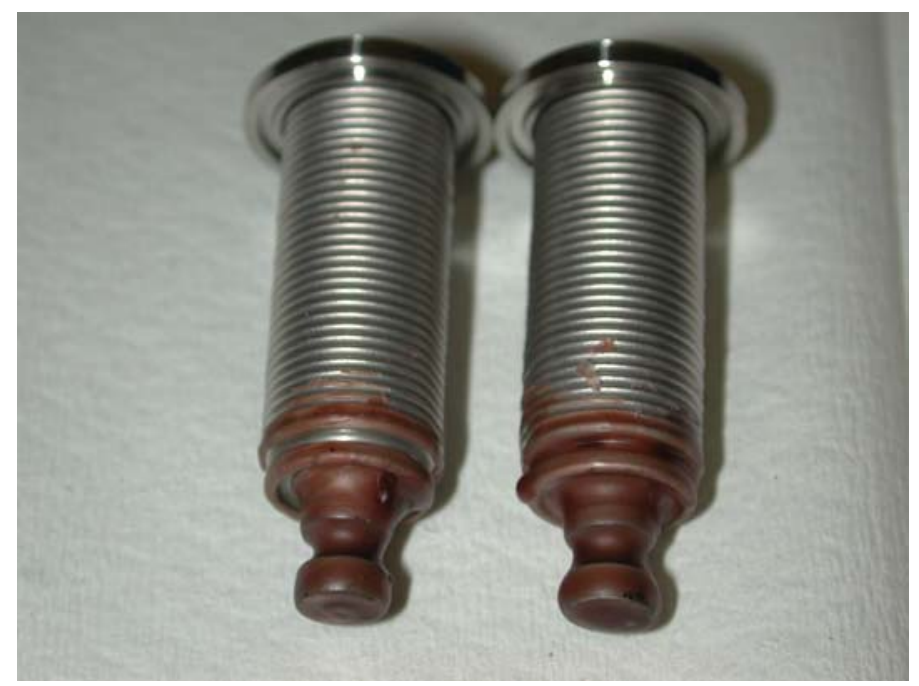

Fig. 3. New bellows assemblies, showing wax-coated tips.

The first two bellows assemblies (bellows A and B) were partially immersed in approximately $25 \mathrm{~mL}$ of a $33 \% \mathrm{HF}$ mixture so that the lower half of the bellows (large end with flange) was submerged under the aqueous HF. Each bellows assembly was assigned a separate Teflon beaker to avoid cross-contamination. Although the $33 \% \mathrm{HF}$ mixture used a technical-grade HF, the mixture was not kept extremely pure, in order to more accurately simulate actual conditions in the system. (The bellows in the system would not be exposed to pure HF but rather to a mixture of HF and corrosion products, and the metal ions in HF are known to change corrosion rates and characteristics.) Bellows A was removed during the short-term testing and allowed to air dry. Corrosion products were allowed to build up on its surface to mimic the accumulation of corrosion products on the surface of a bellows during the actual process. This approach should indicate if a layer of corrosion products had any effect on the rate of corrosion. Each time that bellows B was removed from the HF, it was rinsed in tap water and placed in an ultrasonic cleaner to remove corrosion products. After corrosion products were removed, the bellows was again rinsed in tap water, then rinsed in methanol, and allowed to dry. 
During short-term testing, both bellows were weighed at the end of the day before being reimmersed in their respective beakers.

It was decided that the other two bellows assemblies (bellows $\mathrm{C}$ and $\mathrm{D}$ ) should be tested in such a way that there could be no effect of outside contamination on the rate of corrosion for either bellows. A new mixture of $33 \% \mathrm{HF}$ was prepared using technicalgrade HF and deionized water. New polyethylene beakers and bottles were used to eliminate the potential for any "memory," a condition in which trace amounts of a previous solution might leach out of the surface of the plastic. The handling of the bellows was also performed by using nonmetal tongs assigned to separate beakers, thereby eliminating the unwanted introduction of trace ions. After the stainless tips of the bellows were coated in wax, the bellows were partially immersed in their respective beakers. Bellows $\mathrm{C}$ followed the drying and weighing regimen of bellows $\mathrm{A}$, while bellows $\mathrm{D}$ closely followed the cleaning, drying, and weighing of bellows $\mathrm{B}$, with one exception. To avoid the introduction of new metal ions, bellows D was always rinsed and cleaned in deionized water instead of tap water.

\section{RESULTS}

After each bellows assembly was dipped in wax, the total weight of each of the new bellows varied by no more than $0.2 \mathrm{~g}$ from the weight of the others. Bellows $\mathrm{A}$ and $\mathrm{C}$ gained about $1 \mathrm{wt} \%$ after one cycle, and their weight changes were about the same throughout the 7-day short test. The weights for bellows A and C dropped slightly on days 6 and 7, respectively. However, this decrease can be partially attributed to the loss of wax from the stainless steel tip. At the end of the short-term testing, their weights were only $0.6 \mathrm{wt} \%$ apart. Bellows $\mathrm{A}$ and $\mathrm{C}$ continued to follow a similar pattern as they both slightly gained weight through the 14th day of testing. The now-unprotected stainless steel tips continued to experience major corrosion in the HF vapors, and a large piece of corrosion product and wax came off bellows $\mathrm{C}$ just before day 21. This caused

the weights to diverge as bellows A continued to gain weight and bellows $\mathrm{C}$ suddenly lost weight. The following week bellows $\mathrm{C}$ resumed its weight gain and bellows $\mathrm{A}$ lost some corrosion products. The bellows appear to be largely unaffected except for the 
appearance of some pitting on the flanges and severe corrosion on the stainless steel tip. At the end of the test, on both bellows A and C large corrosion deposits had built up on the area that was above the liquid and especially around the stainless tip (see Fig. 4). Both were cleaned ultrasonically in warm water, but the deposits were unaffected. Bellows A was manually scraped, and $1.34 \mathrm{~g}$ of corrosion deposits was removed. This resulted in a final bellows weight of $26.92 \mathrm{~g}$ and a total loss of $4.16 \mathrm{wt} \%$. The corrosion on bellows $\mathrm{C}$ was left intact but was estimated to approximate the corrosion deposit on bellows A. Bellows C was estimated to have a final weight of $26.54 \mathrm{~g}$ and a loss of $5.99 \mathrm{wt} \%$. It is apparent that most of the weight loss for both bellows $\mathrm{A}$ and $\mathrm{C}$ can be attributed to the normally non-wetted stainless steel tip.

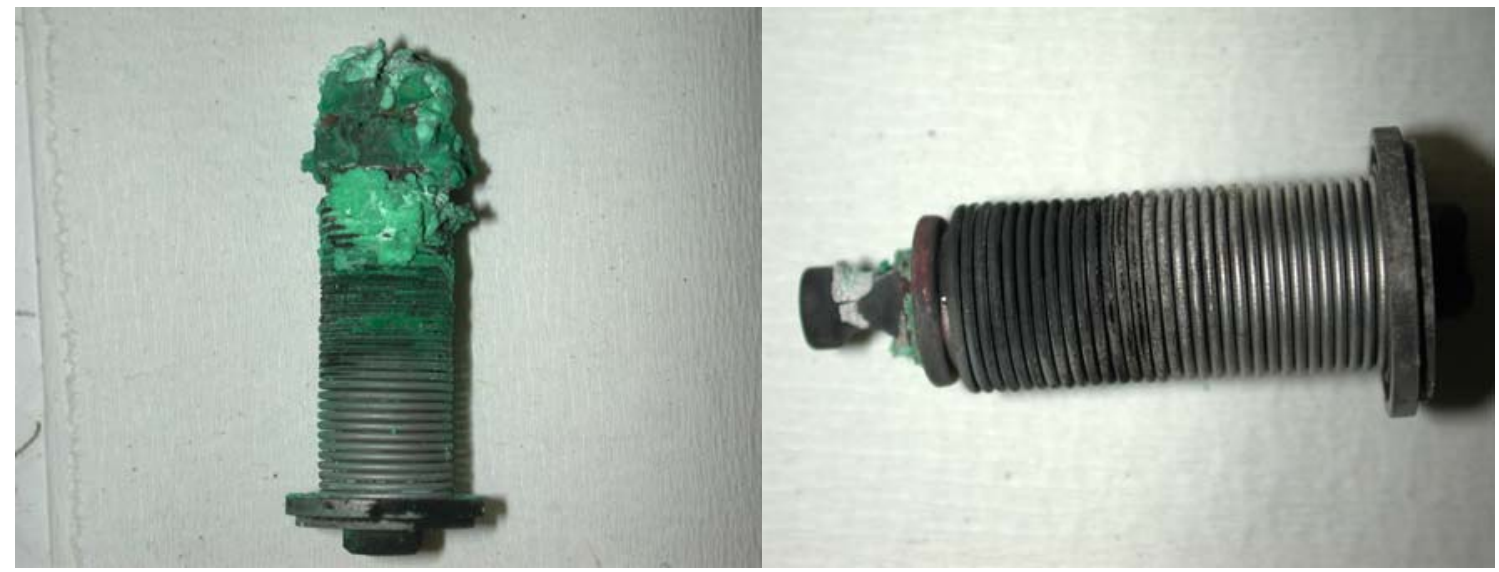

Fig. 4. Bellows $C$ (left) and $D$ (right) at the end of testing (28 days).

Bellows B performed differently from all of the other bellows tested in that it was immediately and severely attacked by the HF. After only 1 day of testing, it lost more than $4.5 \mathrm{wt} \%$ and the HF turned dark green. Upon removal from the HF on day 2, the flange fell off and testing on bellows B was stopped. The bellows was ultrasonically cleaned, rinsed, dried, and weighed, revealing that it had lost a total of $9.5 \mathrm{wt} \%$ since the start of the test. Large deposits of green material covered the bottom and side of the beaker, and the wax covering the stainless steel tip was cracked and expanding. 
Bellows D had a slight weight gain during the first 3 days of the test, but its weight gradually began to decline on days 6 and 7. By the end of the short-term test, bellows D had lost almost $3 \mathrm{wt} \%$. Again, part of this decrease can be attributed to the loss of wax protecting its stainless steel tip during this time. At the end of day 14, the bellows had lost just over $5 \mathrm{wt} \%$. It continued to lose another $0.2 \mathrm{wt} \%$ by day 21 , before experiencing a large loss of $3.4 \mathrm{wt} \%$ the final week. Overall, with the exception of $\mathrm{B}$, it was the most severely attacked and lost a total of $8.65 \mathrm{wt} \%$. Because it was ultrasonically cleaned and rinsed at the end of each cycle, very little corrosion remained on bellows $\mathrm{D}$ at the end of the test. Figure 5 illustrates the weight losses and gains for bellows $\mathrm{A}, \mathrm{C}$, and $\mathrm{D}$ throughout the test.

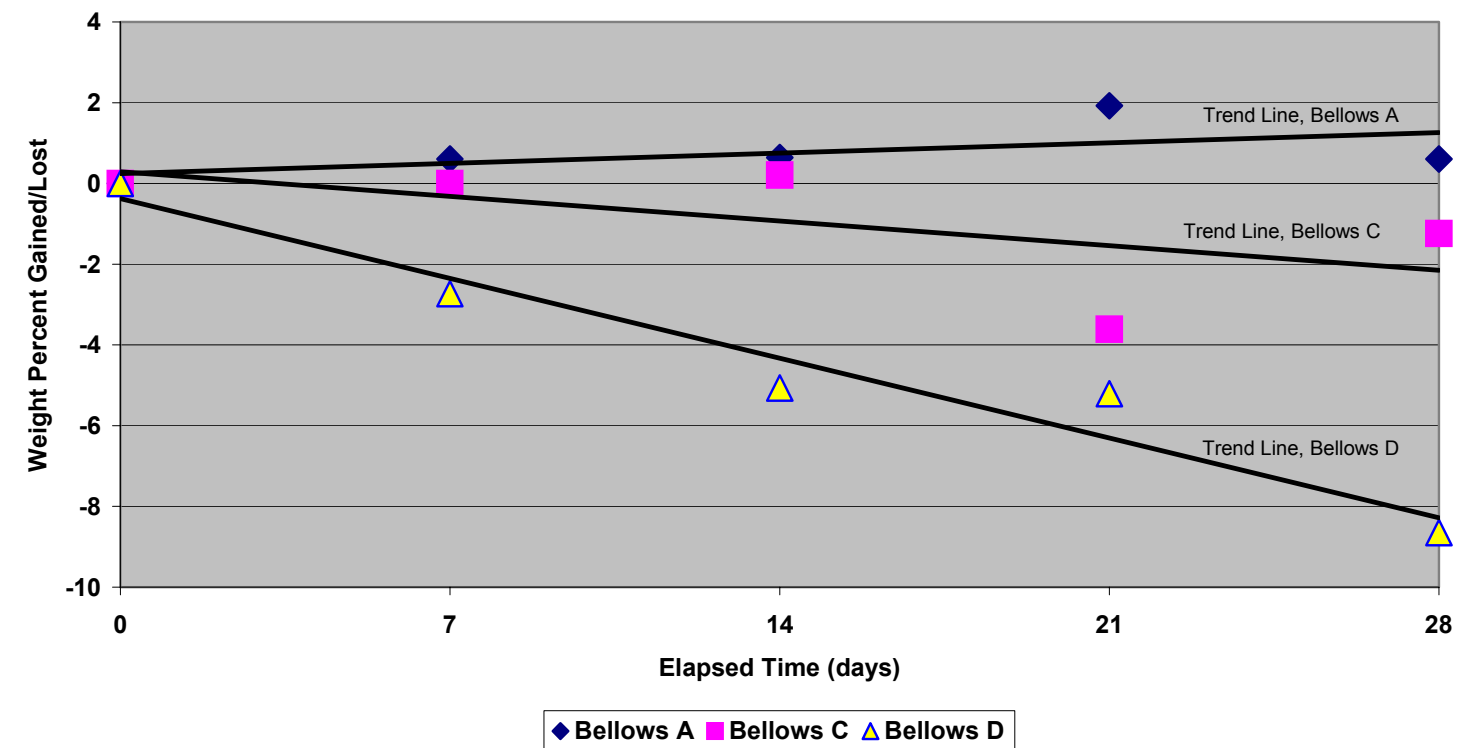

Fig 5. Corrosion test results for Inconel bellows. 


\section{DISCUSSION}

Except for one of the bellows, the results from the short-term (1-week) test were good. The bellows in question, bellows B, experienced catastrophic failure after only two cycles. The bellows came apart between the convolutions just above the flange (see Fig. 6).

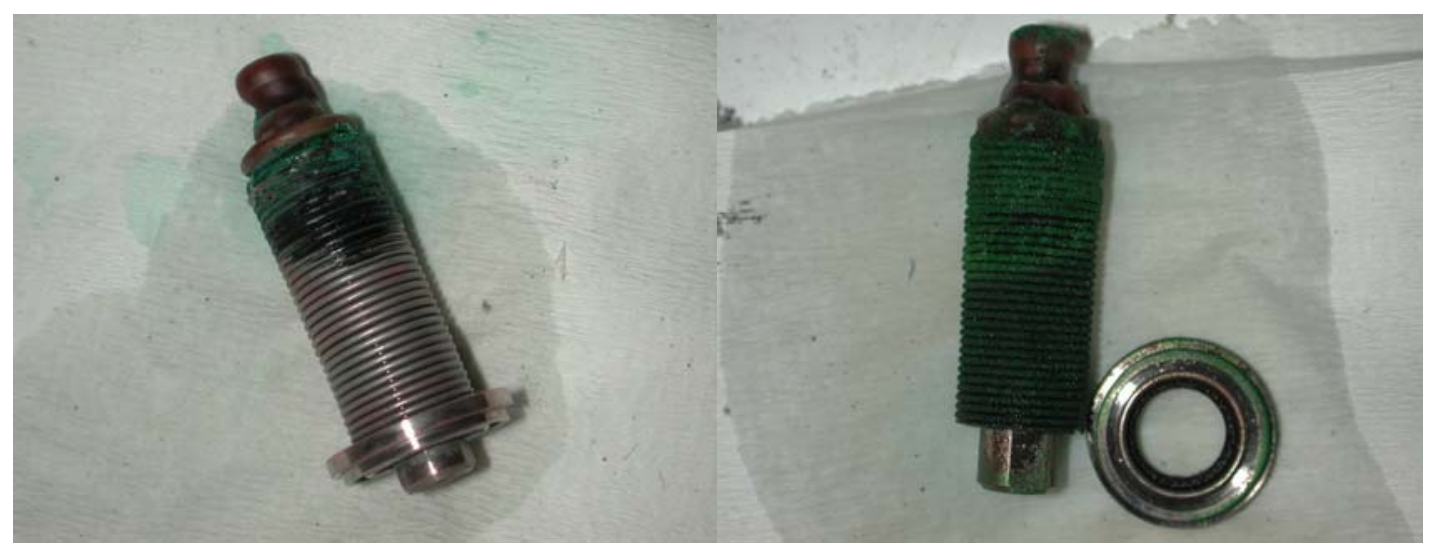

Fig. 6. Comparison of bellows A (left) and B (right) after $32 \mathrm{~h}$ of HF exposure.

Both parts of the bellows assembly were returned to the vendor for analysis, and it was determined that a stainless steel bellows had been inadvertently welded to an Inconel flange. Figure 2 shows the effect of aqueous HF on stainless steel (i. e., on the chemically similar $254 \mathrm{SMO}$ ). The vendor is currently investigating how this stainless steel bellows could have been shipped as an Inconel bellows.

Based on visual observation and weight loss, the new all-Inconel bellows appear to be more resistant to corrosion than the old design. This finding is consistent with those of other published corrosion studies. Bellows $\mathrm{A}$ and $\mathrm{C}$ were removed from the aqueous $\mathrm{HF}$ and dried before weighing. Because they were not cleaned, corrosion products accumulated on the part of the bellows that was exposed only to vapor, and especially on the stainless steel tip (see Fig. 7). This layer of corrosion deposit appeared to contribute slightly to protection of the surface of the metal, and for this reason, bellows A and C experienced less weight loss. Approximately $1-2 \%$ of the weight loss in bellows A, C, and $\mathrm{D}$ can be attributed to the loss of wax coating from the stainless steel tip. 


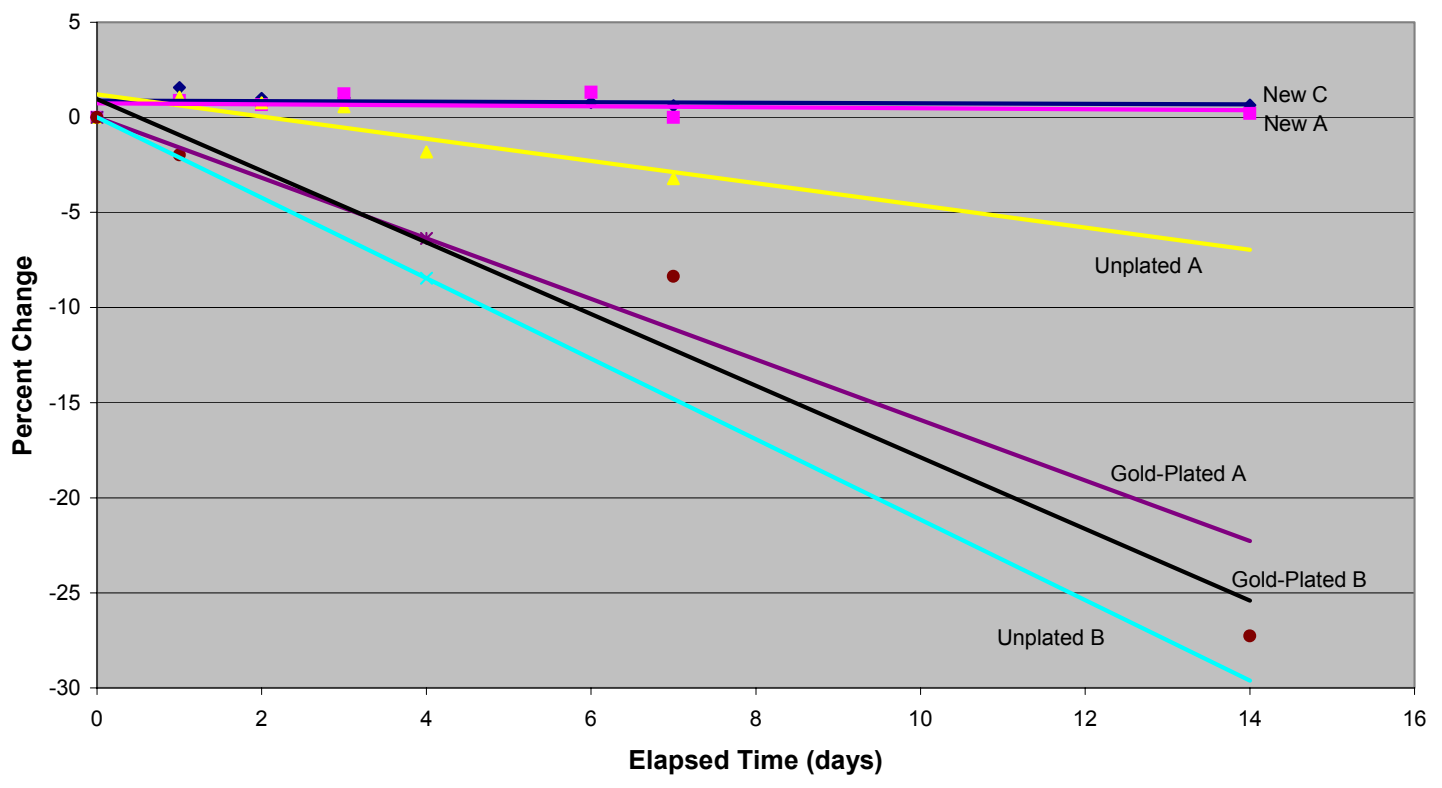

Fig. 7. Percent weight change in corrosion testing of new (all-Inconel) unplated, old (Inconel-stainless) gold-plated, and old unplated UG bellows.

Bellows D, which was ultrasonically cleaned and rinsed at the end of each cycle, experienced the most severe corrosion of the three Alloy 600 bellows. Because it had no protective fluoride films, bellows D had greater corrosion and weight loss. Thus, the metal was freshly exposed at the beginning of each cycle.

The performance of all-Inconel bellows $\mathrm{A}$ and $\mathrm{C}$ was compared with that of four of the old Inconel-stainless bellows (identified as "Unplated A," "Unplated B," "GoldPlated A," and "Gold-Plated B"), which were subjected to a similar testing regime. The new all-Inconel bellows appear superior in every way. The old bellows lost an average of $5.5 \%$ of their weight after 4 days, while bellows assemblies $\mathrm{A}$ and $\mathrm{C}$ actually had a slight weight gain at 4 days due to corrosion products. These results became more dramatic as the testing moved on to day 7 (see Fig. 7). By following the trend lines, it is estimated that the old (Inconel-stainless) bellows would lose close to $10 \%$ of their total weight in the first week while the new (all-Inconel) bellows appear to remain fairly stable during this same time period with no discernible weight loss. 
Based on reports in the literature and the results of this test, it is clear that the allInconel 600 bellows is superior to the Inconel-stainless bellows for the CP applications. Actual use in the CP will produce different corrosion rates from what was observed. However, findings in the literature indicate that the corrosion of Inconel 600 in HF vapor is almost one-fourth that of Monel 400 given the same parameters. The wetted parts in the system should be exposed more to HF vapor than to liquid and therefore should follow the same principle. The testing data and the associated literature study conclusively show the new all-Inconel bellows to be superior to the old Inconel-stainless bellows, including those that were gold plated. 


\section{REFERENCES}

1. R. B. Rebak, J. R. Dillman, P. Crook, and C. V. V. Shawber, "Corrosion Behavior of Nickel Alloys in Wet Hydrofluoric Acid," Mater. Corros. 52, 289-297 (2001).

2. S. J. Pawel, "Corrosion of High-Alloy Materials in Aqueous Hydrofluoric Acid Environments," Corrosion 50(12), 963-971 (1994).

3. C. M. Schillmoller, "Select the Right Alloys for Hydrofluoric Acid Service," Chem. Eng. Prog. 94, 49-54 (November 1998).

4. M. Schussler, "Metal Materials for Handling Aqueous Hydrofluoric Acid," Ind. Eng. Chem. 47, 133-139 (January 1955).

5. "Corrosion Resistance of Nickel-Containing Alloys in Hydrofluoric Acid, Hydrogen Fluoride, and Fluorine," Inco Corrosion Engineering Bulletin No. 5, International Nickel Co., Inc., New York, 1968. 


\section{INTERNAL DISTRIBUTION}

1. J. M. Begovich

2. C. W. Chase

3. G. E. Chitwood

4. J. M. Cosgrove

5. G. D. Del Cul

6. R. L. Faulkner

7. D. Foster

8. M. H. Haghighi, Bechtel Jacobs Company

9. J. N. Herndon

10. A. S. Icenhour

11. R. A. Kite

12. P. E. Osborne

13. B. A. Owen
14. J. H. Platfoot

15. S. A. Richardson

16. J. E. Rushton

17. D. W. Simmons

18. J. R. Travis

19. M. G. Branton, DOE ORNL Site Office

20. M. R. Jugan, DOE-ORO

21. S. R. Martin, DOE ORNL Site Office

22. Central Research Library

23. ORNL Laboratory Records

24-25. ORNL Laboratory Records - OSTI-RC

26. NSTD DMC

27. Conversion Project Files

\section{EXTERNAL DISTRIBUTION}

28. Don Lewis, 3919 Papermill Drive, Knoxville, TN 37909 